The Encouragement of Medical Discovery.

THE article on medical research in NATURE of April 5 hits the nail on the head. Great Britain is now spending, I suppose, something like a quarter of a million pounds a year on subsidised medical researches; but as you say, "Research and original investigation of the highest kind are the work of the individual, and first-class researchers occur sporadically but a few times in a generation" - and the nation does nothing at all to encourage these men at present. I have no doubt that the subsidised workers are all doing their best, but we as a nation do not seem quite to understand the fact that discoverywhich is the final crown of research-is rarely achieved except by people who possess a very specialised order of intellect. In the past the men who have actually made the most important advances in medical science have been volunteers, and often, like Harvey, Jenner, Pasteur, Lister, Laveran, Koch, and many others, were not subsidised or paid at all, at least when they began their labours. In my opinion, out of 30,000 or more medical men in Great Britain, there may be many or several potential Harveys and Jenners, but owing to the absence of any payment whatever, even for the most successful but privately made discoveries, such potential workers do not allow themselves to indulge in the pleasures (or pains) of scientific investigation.

My opinion is that the money which we are now giving for subsidised researches should be supplemented by some form of national payment for unsubsidised discoveries already completed. We are now paying large sums for prospective discovery but nothing at all for discovery already achieved. In I 920 the British Science Guild proposed an excellent scheme for pensions for achieved results in medical science, costing, I suppose, less than a tenth of the money which the nation now pays for subsidised research; but our scheme was turned down by the Government of that day for reasons which appeared to me to be quite trivial and unsound. Would it not be advisable, now that we have a Government which is supposed to appreciate the value of labour, to attempt to resuscitate this scheme, and thus to persuade the nation to pay honourably for professional benefits received by it in the line of medical discovery? RONALD RosS

4I Buckingham Palace Mansions,

London, S.W.I.

\section{Mendelism and Evolution.}

IN his review of Morgan's "The Mechanism of Mendelian Heredity" Mr. Huxley refers to my letter in NATURE of January I2, saying, that if he reads me aright I approve of the idea, expressed as a mere suggestion by Johannsen, etc. I have read my letter again and $I$ must say that it seems to me to be perfectly straightforward and to offer no excuse whatever for reading into it anything that I did not write Consequently, there is no need for me to reply to the questions that Mr. Huxley puts to me. However, his remarks about the hostility of Darwinians to Mendelism, their refusal to make use of it, etc., lead me to think that it may perhaps be worth while to make my own position clear.

In a study of the structure, classification, and geographical distribution of fishes, carried on for more than twenty years, my method, whether I was engaged with orders and families, or with genera and species, was always the same; this was, from a consideration of all the available data, to form conclusions as to relationships, and to try to express these in classification. After comparing my own results with those obtained from other groups, and after considering the evidence from palæontology and embryology, I think that I have good reason to believe that evolution has been a slow and gradual process, that in its main lines it has been adaptive, and that changes of structure have been intimately related to and even determined by changes of function; further, that as a rule the first step in the origin of a new species is the formation of a community with a new or a restricted environment, or with new habits; in other words, that some form of isolation, either localisation or habitudinal segregation, is a condition of the development of a new species.

In many instances the evidence is clear as to what has happened, and when and where it has happened; there are even indications why; but the problem that remains to be solved is how!

I have read several books by eminent Mendelians, which contain some very definite statements as to the methods of evolution and some strong criticisms of Darwin; but the impression left on my mind is that Darwin knew the nature of the facts that had to be explained, and gave us a theory that explained them, and that his Mendelian critics are not acquainted with the real nature of the problem. But this is not hostility to Mendelism. Surely one may admire the results obtained by Mendelian research, results of great theoretical interest and practical value, even if one has to admit that this work in a very special and limited field cannot be expected to give us a complete theory of evolution.

Evolution has been such a long and slow process that we may well doubt whether experiments made by man will ever succeed in repeating, except to a slight extent, what has happened under natural conditions. But we may at least hope that experiments of the right sort may perhaps lead to something. A thorough comparison of the structure and the lifehistory of two related species should reveal the meaning of some of their specific characters in relation to habits and environment, and thus show the lines on which experiments should be conducted in the attempt to produce modifications of the same nature.

C. Tate Regan.

I AM sorry to have misinterpreted Mr. Tate Regan, but I assumed, I think not unnaturally, that what he quoted, he quoted with approval. In the circumstances, my criticisms fall only upon the quoted statement and its author.

As an example of what I meant by the failure by workers in other fields of zoology to take account of genetic methods and results, and the failure even to attempt experimental solutions, I may refer to two recent papers by Annandale (Annandale, Proc. Roy. Soc. B, I924, 96, p. 60 ; and Annandale and Hora Rec. Ind. Mus. I922, 24, p. 505) on molluscs and aquatic vertebrates respectively, in which, on the basis of field observations (often of the most interesting nature), certain evolutionary theories are put forward.

Of Dr. Annandale's work in the faunistic and geological fields, it is unnecessary, and would be impertinent, for me to speak; every one knows its soundness and brilliance. But to attempt to raise any theory of the method of evolution on observational data alone, is so unthinkable to the experimentalist that he scarcely knows where to begin his criticisms.

When we remember that Dr. Annandale does not know (and cannot, for he records no experiments) what part of each character he deals with is due to germinal influence, and how much it is capable of being modified by environment; that he does not know whether he is dealing with a homogeneous or a mixed population; nor whether possible hereditary

$$
\text { NO. } 2842 \text {, VOL. I I } 3]
$$

